\title{
AN ASSESSMENT OF SAFETY AT SIGNALIZED INTERSECTIONS POST RESURFACING
}

\author{
N. HUSSEIN \& R. HASSAN \\ Swinburne University of Technology, Australia.
}

\begin{abstract}
Crash records for a sample of signalized intersections have been analysed to assess the effect of surface treatment. Analysis of crash data (all types and severity levels) for 3-5 years before and after resurfacing year showed a reduction in rate. Effectiveness of treatment in achieving statistically significant reduction in crashes was confirmed by Empirical Bayes (EB) approach. Overall trends of crash frequency before and after treatment against surface condition in terms of roughness, rut depth and skid resistance were also investigated. The results showed that the trend of crash rate correlates positively with roughness and negatively with skid resistance and rut depth. This trend was true for both before and after crash data. Time of day and moisture condition of the surface proved to strongly influence crash frequency with wet surface during night-time being associated with lower frequency than dry surface at daytime.
\end{abstract}

Keywords: crash frequency, crash rate, Empirical Bayes, roughness, rutting, safety effectiveness, signalized intersection, skid resistance.

\section{INTRODUCTION}

Understanding the contribution of factors that affect performance of signalized intersections is important for addressing safety concerns. Some of these factors are related to the road itself. Such factors include traffic volume and composition, speed, geometry, condition of line marking and signage, signal phasing, light condition and surface condition. It is believed that adequate level of pavement condition does not only improve operational performance of signalized intersections but also results in considerable reduction in crashes. The study reported herein involves a before and after study of crash data at signalized intersections sites that were subject to resurfacing with a thin asphalt layer. These sites consist of granular pavements (crushed rock bases and sub-bases) with thin asphalt surfacing and located in a metropolitan region of Australia. The objectives of study are the following:

1. To better understand the effects of pavement condition parameters on crash rates at signalized intersections. They include surface roughness (in terms of the International Roughness Index (IRI)), rutting (in terms of rut depth (mm)) and skid resistance (in terms of sideway friction coefficient (SFC)). This is in addition to situational factors including light condition and surface moisture condition.

2. To evaluate safety effectiveness of improvements in pavement condition due to surface treatment. 


\section{BACKGROUND}

Provided in this section is a summary of findings from past published studies on safety effectiveness of resurfacing and the effects of the condition parameters stated above on crash rates. These studies involved using different methodologies and cover different locations (intersections and road links) and operating environments (rural and urban). The summary of findings is presented in Table 1, from which the following can be inferred:

- Generally, resurfacing is effective in reducing crash occurrence but varies in extent by crash type and severity. In few cases there has been an increase in crashes which is related to increased speed with the new surfacing.

- No clear relationship between roughness with crash occurrence at signalized intersections.

- Deep ruts may contribute to crash occurrence particularly in wet nights.

- Improving skid resistance has a great impact on crash frequency reduction.

- More crashes occur during the day than at night and night crashes in lit streets are less frequent than in unlit streets and associated with lower severity.

\section{ASSESSMENT DATA AND APPROACH}

\subsection{Site selection}

Crash data for the study area was available between 2000 and 2013. For this study, all signalized intersections that were subject to resurfacing during the period of 2005-2010 were identified. This period was selected as it is the period over which relevant condition data (roughness and rutting) was available for one year before and after treatment years. Further, within this period, crash data was available for each intersection over 5 years before and a minimum of 3 years after treatment year (NZTA [1]). The final set of treated sites had a sample size of 136 .

Table 1: Summary of findings from published literature.

\begin{tabular}{ll}
\hline Reference & Findings \\
\hline Hauer et al. [2] & $\begin{array}{l}\text { Non-intersection crashes increased by } 21 \% \text { for projects } \\
\text { involving only resurfacing but safety improved for projects } \\
\text { where additional improvements accompanied the resurfacing. }\end{array}$
\end{tabular}

Abdel-Aty et al. [3]

Pardillo Mayora and Jurado Pina [4]

Zeng et al. [5]

Chan et al. [6]

Cairney and Bennett [7]
Total number of crashes increased by $62 \%$ at the resurfaced sites. However, the rear-end crashes reduced by $0.83 \%$ and severe crashes reduced by $4.63 \%$.

Resurfacing significantly reduced wet-pavement crash rate by an average of $68 \%$.

Resurfacing treatment was significant in reducing fatal and injury crashes by $26 \%$ but was not effective in reducing total crash frequency.

Crash rate increased with IRI and that this was more pronounced in wet weather conditions and at night than in dry weather conditions and during daylight.

High correlation between roughness and crash occurrence on road segments. 
Larson et al. [8]

Cairney and Bennett [9]

Tighe et al. [10]

Cairney et al. [11]

Chan et al. [6]

Candappa et al. [12]

Saplioglu et al. [13]

Simpson and Eng [14]

Pardillo Mayora and Jurado Pina [4]

Khattak [15]

Yan et al. [16]

Wang and Abdel-Aty [17]

Hollo and Kajtar [18]

Golob and Recker [19]
No strong relationship between wet or total crashes and average IRI for signalized intersections.

No relationship between roughness and crash occurrence at urban signalized intersections.

Single-vehicle crash rate decreased with an increase in road roughness but multiple-vehicle crash rates increased.

Crash risk related to rutting increased in the deepest rutting sites only.

Rut depth did not affect crash prediction models significantly except for night and weather-related crashes.

A reduction of about $44 \%$ in casualty crashes when skid resistance was improved with surface treatment.

There is a significant reduction in crash rates as skid resistance increased.

A reduction in number of crashes of $39 \%$ in areas treated with high skid resistant surfaces.

A significant decrease in crash rates as skid resistance increases in both wet and dry pavement conditions. They reported an average of $68 \%$ reduction in wet-pavement crash rate after resurfacing.

$54.9 \%$ of crashes occurred during the day at both morning and evening peak hours. Also that only $10.8 \%$ of crashes was related to night with unlit street condition and $4.9 \%$ on lit street condition.

Daytime crashes constitute $71.7 \%$ and night-time crashes $28.3 \%$ of total crash frequency.

Crashes occurred at night with street lights were associated with lower crash injury level.

A strong correlation between crashes occurring during the night with wet condition than crashes during the day and dry conditions.

Rear-end crashes are likely to be related to day-dry condition and crashes involving more than one vehicle are likely to be related to wet surface condition.

This study is considered fully controlled as the same intersections were used before and after treatment so the only variation was related to surface condition. All other road-related factors that may affect crash occurrence including speed limit remained unchanged. Line marking condition has also been checked and found to be in good condition before treatment and in new condition after. It is important to note that resurfacing treatments applied do not cover the whole intersection. They may cover the intersection centre and/or its approaches (immediate $200 \mathrm{~m}$ ). The total length of treatment that was used in the analysis ranged between 100 and $500 \mathrm{~m}$. Records of skid resistance data were only available for the period 2006-2011. This resulted in identifying only 57 out of the 136 sites with all condition data being available 
one year before and after treatment. It is important to note that the effect of the variation in traffic volumes for the years before and after treatment was controlled by using crash rates instead of frequencies when assessing the change in crash occurrence in trend analysis, however, crash frequency was used for evaluating the change by EB approach.

\subsection{Data preparation}

Crash data collected included all casualty crashes, i.e. covering all severity levels (fatal, serious injuries and other), type of crash (head-on, rear, etc.), light condition when they occurred (day or night), road surface moisture condition (wet or dry) and speed limit. To provide a balanced analysis, an equal period of crash data for before and after treatment for each intersection has been selected and the longest available period for each intersection (i.e. either 3, 4 or 5 years) has been used. Crash rates for each site, before and after treatment, were determined by dividing total traffic volumes covering the same period over which crash data is available by the total number of crashes. Crash rates are reported in terms of number of crashes per 10 million vehicles entering the intersection (10 MVE) (Austroads [20]). Traffic volume data used was in terms of annual average daily traffic (AADT) that used the section of road where the intersection site is located, along the approaches where crashes took place.

Surface condition data including roughness, rutting and skid resistance of the treated direction of each site was collected for one year before treatment year and one year after. Roughness is reported in terms of lane IRI (average of two wheel paths) in $\mathrm{m} / \mathrm{km}$ and rut depth in mm for each $100 \mathrm{~m}$ segment. Data of skid resistance is collected for both wheel paths using sideways force coefficient routine investigation machine (SCRIM) and reported for each separately and their average in terms of sideways force coefficient (SFC) values, also for $100 \mathrm{~m}$ segments. Data documented by SCRIM is a positive integer equivalent to SFC*100.

For the analysis performed herein, data of each condition parameter for each site was averaged over a length of $500 \mathrm{~m}$, covering the intersection centre and a maximum of $400 \mathrm{~m}$ of its approaches. The selected $500 \mathrm{~m}$ section is along the leg that includes the treated section and location of crashes. It is important to note that treatments of pavements at intersections and their approaches are currently triggered by surface distress ratings, referred to as surface inspection rating (SIR), regardless of roughness level. SIR of an asphalt surfacing is a composite index of the ratings for cracking, stone loss, texture loss, patching, and deformation (VicRoads [21]).

\subsection{Assessment approach}

The effects of the three pavement condition parameters on crash rates were assessed using trend analysis using data of 136 sites for roughness and rutting and 57 sites for skid resistance. This was applied to casualty crashes only in both before and after the year of surface treatment and considering relevant situational factors.

The evaluation of safety effectiveness of improvements in pavement condition of 136 treated sites was conducted using Empirical Bayes (EB) approach. The primary goal for EB technique is to compare observed crash data for before period with crash data in the after period for same site. The advantage of using EB over the other available approaches is that it accounts for regression to the mean (RTM) bias, traffic volume change through using safety performance function and time trend (Hauer et al. [22]). This can be done by comparing the 
expected number of crashes for the after period had the treatment not been implemented with the reported number of crashes during the after period. This is based on using reference sites with similar traffic and other site characteristics (Persaud and Lyon [23], Gross et al. [24]). The number of reference sites identified that have not been treated during the study period is 66. This assessment has been applied to total casualty crashes, high severity (fatality and serious injury) crashes and other injury crashes.

\section{ASSESSMENT RESULTS AND DISCUSSION}

\subsection{Assessing the effect of pavement condition}

The effects of changes in surface condition on intersection safety performance due to surface treatment are assessed here through observation of trends from graphs. For trend analysis, the data of each condition parameter has been divided into groups or categories, each covering a certain range. Crash rate that corresponds to a certain category is the average value of crash rates for all intersections with condition parameter that falls within that category. The variation in crash rates with surface roughness for both before and after treatment is presented in Fig. 1a. There is a clear positive trend where crash rate increases with roughness and that is true for both before and after treatment data in addition to that it is higher before treatment than after. Some of the sites after treatment are associated with relatively high roughness $>3 \mathrm{~m} / \mathrm{km}$. The reason for this is related to the fact that roughness level is not considered in treatment selection so a thin layer of asphalt resurfacing might not fix all profile characteristics contributing to roughness. Additionally, not all $500 \mathrm{~m}$ sections have been treated and during

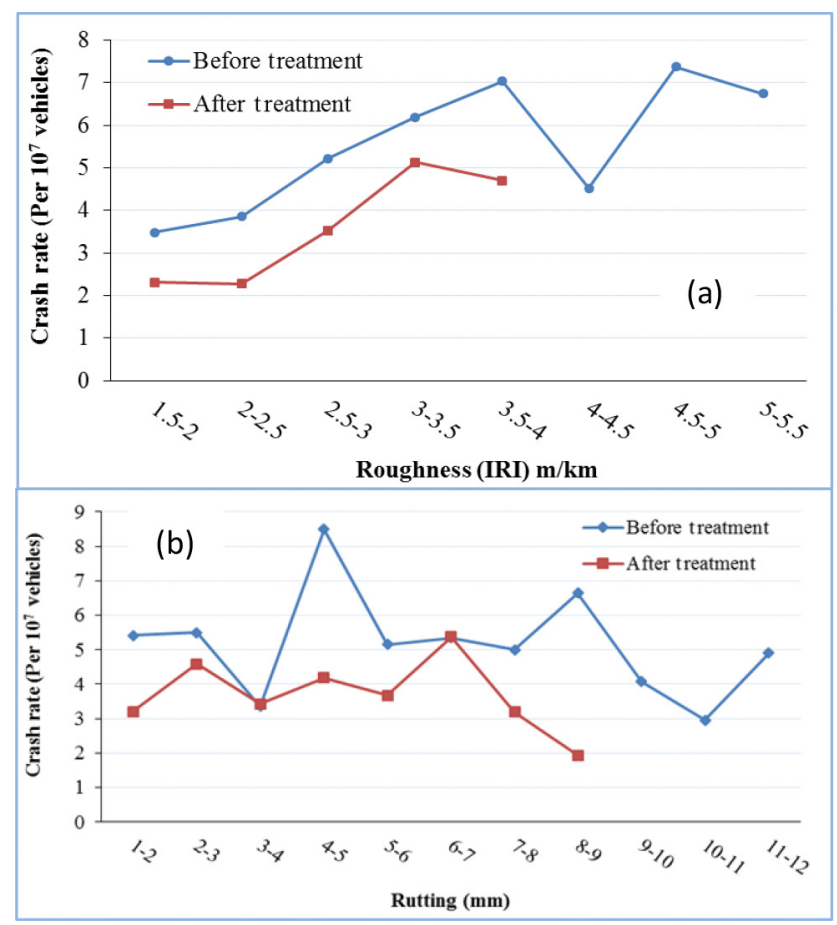

Figure 1: Casualty crash rate vs roughness (a) and rutting (b) categories. 
the three years including the year of treatment and the years before and after, roughness of the untreated sections would have increased.

The crash rates associated with different rutting categories are also presented in Fig. $1 \mathrm{~b}$. The overall trend for crash rate with rutting categories seems negative, indicating lower crash rates where deeper ruts exist. This is true for both before and after treatment data with the only difference; that is, the first includes deeper ruts and higher crash rates than the second. The negative trend could be related to the fact that drivers slow down and are more alert when they see deep ruts hence reducing crash occurrence.

Additionally, it has been observed that regardless of roughness level or rut depth, crash rates vary significantly with time of day and surface moisture condition. Crash frequency during the day/dry surface is higher than at both night/wet and dry surfaces as can be noticed in Fig. 2. This could be related to higher traffic movements during daytime and dry conditions. There is no results for crash type in the paper. The variation in crash rates with skid resistance in terms of SFC, for both before and after treatment, is presented in Fig. 3 for wet and dry conditions. The overall trend seems negative, indicating lower crash rates with higher SFC categories and that is true for both before and after treatment data except that it is clearer for after treatment. Other observations can be summarized as follows:

- For both data sets, crash rate in wet surface conditions is significantly lower than in dry surface, regardless of SFC values.

- After treatment, crash rate peaks at SFC of 0.5-0.55 and before treatment; it peaks at the same range and at a high SFC range of 0.6-0.65.

- For both dry and wet surface conditions generally smaller percentages of crashes are associated with very high SFC categories. Overall it seems that crashes occur at all ranges of skid resistances with varying frequencies.

\subsection{Evaluating safety effectiveness}

Data from the reference sites was used to develop safety performance function (SPF) using negative binomial (NB) regression (Gross et al. [24]). SPFs are mathematical models that predict crash frequency for similar sites based on traffic volume and other site characteristics. Traffic volume is considered the most important factor in crash prediction models. Hence, the SPF for this study is based on total traffic volume entering the nominated approach of

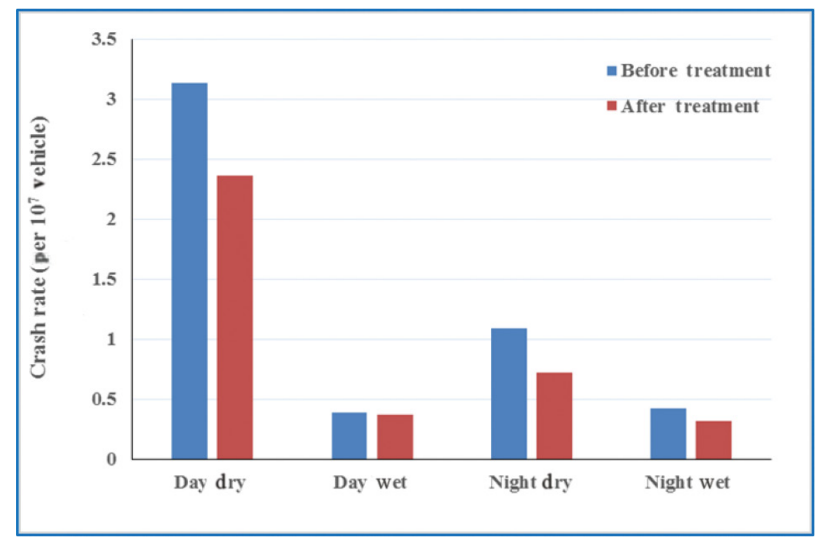

Figure 2: Distribution of casualty crash rates by time of day and surface moisture condition. 

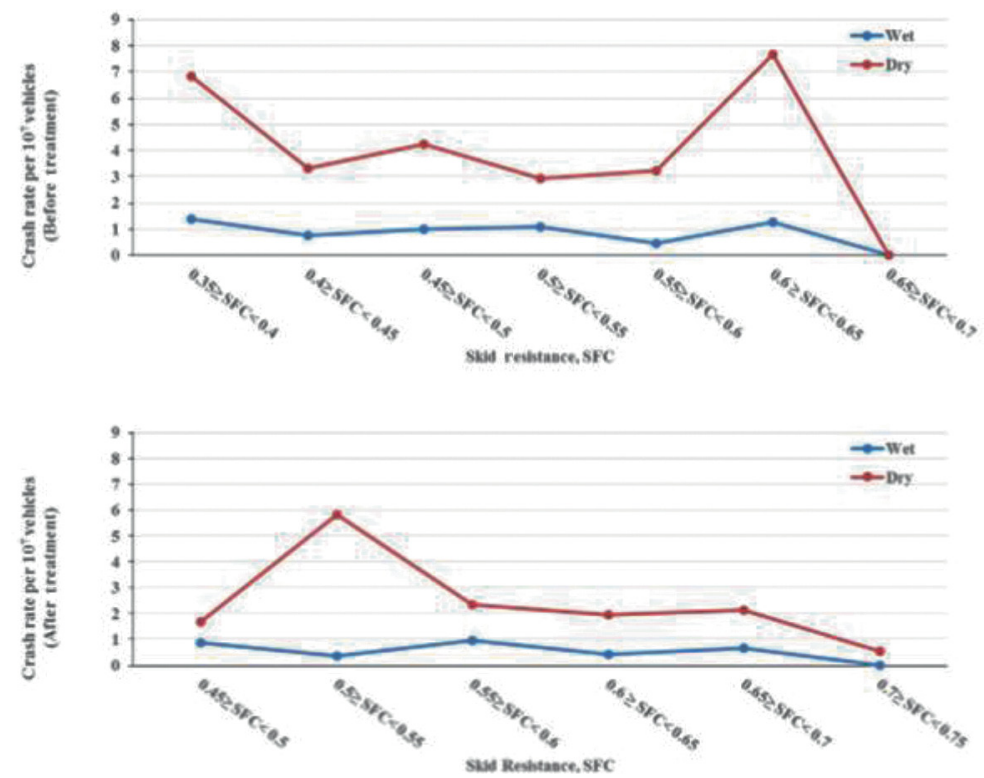

Figure 3: Casualty crash rate vs. skid resistance categories.

each intersection in a reference group. By using relevant information (crash frequency and traffic volume) from both treated and reference sites, the expected number of crashes at treated sites can be estimated. The detailed procedure of EB method described in Highway Safety Manual [25] has been followed to evaluate safety effectiveness of pavement surface treatment, expressed in percentage change in crashes. The analysis was performed on three different crash severity levels including casualty, high severity (fatality and serious injury) and other injury crashes. Total crashes for each of these categories for treated and reference sites before and after treatment and average AADT are summarized below:

- AADT: treated (before 12865, after 13485), reference (before 13395, after 13865)

- Casualty crashes: treated (before 44, after 32), reference (before 31, after 28)

- High severity: treated (before 12, after 18), reference (before 11, after 10)

- Other injury: treated (before 36, after 22), reference (before 21, after 22)

Using generalized linear model (GLM), the SPF models for each crash category were developed and the models' coefficients were estimated, assuming negative binomial error distribution. The primary model form for all SPFs used in this study is presented in eqn (1):

$$
\mathrm{Nspf}=\operatorname{Exp}(\alpha+\beta * \ln (\text { AADT entering }))
$$

Total crash frequency for all severity levels of reference sites and average AADT over 5 years have been used in developing SPFs. A yearly crash prediction model is derived by dividing the 5-year model by 5 (Lord and Persaud [26]). Table 2 provides results of NB regression for developing SPF for all three crash severity levels. The results indicate that the parameters are significant at $95 \%$ confidence level. The dispersion parameters of $0.419,0.357$ and 0.418 for total casualty, high severity and other injury crashes, respectively, are greater than zero which indicates that the dependent variable (crash frequency) is over-dispersed in all three models. 
Furthermore, the values of deviance of 1.224, 1.179 and 1.223 and Pearson chi square of $0.799,0.984$ and 0.827 for total casualty, high severity and other injury crashes, respectively, obtained from the goodness-of-fit criteria are close to the ideal value of one which supports the use of NB model.

Necessary yearly factors such as SPFs multiplier are applied to eqn (1) to account for time trend in EB approach as shown in eqn (2).

$$
\mathrm{N}_{\text {predicted }}=\operatorname{Exp}(\alpha+\beta * \ln (\text { AADT entering })) * \text { Yearly factor. }
$$

These SPFs multipliers were derived for different crash severity levels for each year before and after treatment and are estimated as the total number of observed crashes divided by total number of predicted crashes for a given year (Highway Safety Manual [25]) as shown in Table 3. To account for the difference in duration between before and after period at each intersection the adjustment factor (ri) was calculated as given in the Highway Safety Manual [25].

The overall results obtained from EB approach to evaluate safety effectiveness for pavement condition improvement following treatment are given in Table 4. For total casualty crashes evaluated in this study, the odd ratio (OR) or crash modification factor (CMF) is 0.819 with

Table 2: Results of SPF model development for all crash severity levels.

\begin{tabular}{llll}
\hline Crash severity & Total casualty & High severity & Other injury \\
\hline Parameters & $\begin{array}{l}\text { Estimated value } \\
\text { (standard error) }\end{array}$ & $\begin{array}{l}\text { Estimated value } \\
\text { (standard error) }\end{array}$ & $\begin{array}{l}\text { Estimated value } \\
\text { (standard error) }\end{array}$ \\
Intercept & $1.889(0.23)$ & $0.879(0.25)$ & $1.464(0.23)$ \\
AADT entering & 0.0000288 & 0.0000145 & 0.000034 \\
& $(0.0000149)$ & $(0.0000163)$ & $(0.0000156)$ \\
Dispersion & $0.419(0.09)$ & $0.357(0.13)$ & $0.418(0.11)$ \\
parameter & 1.224 & 1.179 & 1.223 \\
Deviance & 0.799 & 0.984 & 0.827 \\
Pearson chi square & &
\end{tabular}

Table 3: Applied yearly factors for all crash severity levels.

\begin{tabular}{lccccc}
\hline \multicolumn{5}{c}{ Before treatment } \\
\hline Severity level & Year 1 & Year 2 & Year 3 & Year 4 & Year 5 \\
Total casualty & 1.55 & 1.58 & 1.38 & 1.49 & 1.48 \\
High severity (F \& SI) & 1.45 & 1.48 & 1.04 & 1.04 & 1.10 \\
Other injury & 1.24 & 1.40 & 1.30 & 1.46 & 1.37 \\
\hline \multicolumn{5}{c}{ After treatment } \\
\hline Severity level & Year 1 & Year 2 & Year 3 & Year 4 & Year 5 \\
Total casualty & 2.00 & 1.44 & 1.16 & 0.91 & 1.14 \\
High severity (F \& SI) & 1.60 & 1.26 & 1.23 & 0.78 & 0.72 \\
Other injury & 1.75 & 1.17 & 1.00 & 0.72 & 0.76 \\
\hline
\end{tabular}


Table 4: Results of safety effect evaluation by EB before-after study.

\begin{tabular}{|c|c|c|c|}
\hline \multirow{2}{*}{$\frac{\text { Parameters }}{\text { Crash severity }}$} & \multicolumn{3}{|c|}{ EB results } \\
\hline & Total casualty & High severity & Other injury \\
\hline Number of intersections & 136 & 136 & 136 \\
\hline $\begin{array}{l}\text { Total number of crashes observed in } \\
\text { the after period (Nobserved, A) }\end{array}$ & 1,010 & 341 & 667 \\
\hline $\begin{array}{l}\text { Total number of crashes expected in } \\
\text { the after period had the treatment not } \\
\text { been implemented (Nexpected, A) }\end{array}$ & $1,231.71$ & 367.51 & 748.83 \\
\hline $\begin{array}{l}\text { Treatment effectiveness in the form } \\
\text { of odd ratio for all sites, OR }\end{array}$ & 0.82 & 0.928 & 0.891 \\
\hline Var (Nexpected, A) & 882.26 & 172.29 & 424.05 \\
\hline $\begin{array}{l}\text { Unbiased estimate of treatment } \\
\text { effectiveness, OR (crash modification } \\
\text { factor, CMF) }\end{array}$ & 0.819 & 0.927 & 0.89 \\
\hline Safety effectiveness $=100 *(1-$ OR $)$ & $18.1 \%$ & $7.3 \%$ & $11 \%$ \\
\hline $\operatorname{Var}(\mathrm{OR})$ & 0.00106 & 0.00362 & 0.000179 \\
\hline $\mathrm{SE}(\mathrm{OR})=\sqrt{\operatorname{Var}}(\mathrm{OR})$ & 0.032 & 0.0602 & 0.0423 \\
\hline $\begin{array}{l}95 \% \text { Confidence interval }=\mathrm{OR}^{*} \pm \\
1.96 * \mathrm{SE}(\mathrm{OR})\end{array}$ & $0.76-0.88^{*}$ & $0.81-1.05 * *$ & $0.81-0.97 *$ \\
\hline $\begin{array}{l}\text { SE (Safety effectiveness })=100^{*} \\
\text { SE }(\text { OR })\end{array}$ & 3.2 & 6.02 & 4.23 \\
\hline $\begin{array}{l}\text { Abs [Safety effectiveness/SE(Safety } \\
\text { effectiveness)] }\end{array}$ & $5.66^{*}>2.0$ & $1.21 * *<2.0$ & $2.6^{*}>2.0$ \\
\hline
\end{tabular}

* Significant at $95 \%$ confidence level.

** Not significant at $95 \%$ confidence level.

a standard error of 0.032 . For high severity crashes, the OR is 0.927 with a standard error of 0.0602 , and for other injury crashes, OR is 0.89 with a standard error of 0.0423 . The OR is significant (less than 1 ) at $95 \%$ confidence interval of $(0.76-0.88)$ for total casualty and $(0.81-0.97)$ for other injury crashes. This means at least $95 \%$ certain that there is a reduction in crashes after pavement surface treatment (Gross et al. [24]). However, for high severity (fatality and serious injury) crashes the OR estimate of 0.927 is not significant at 95\% confidence interval of 0.81-1.05 since it includes 1.0.

The absolute value of the measure, Abs [Safety Effectiveness/SE (Safety Effectiveness)], for total casualty and other injury crash categories is greater than 2.0 which confirms that the treatment effect is significant at the (approximate) 95\% confidence interval (Highway Safety Manual [25]). These evaluation results suggest that there is a reduction in total casualty crashes by $18.1 \%$ with a standard error of $3.2 \%$, and $11 \%$ with a standard error of $4.23 \%$ for other injury crashes. Furthermore, the results indicate that although there is a slight reduction in high severity (fatality and serious injury) crashes by $7.3 \%$ with standard error of $6.02 \%$, the reduction is found to be not significant at $95 \%$ confidence interval with the absolute value of the measure, Abs [Safety effectiveness/SE (Safety effectiveness)] of 1.22 which is less than 2.0. 


\section{CONCLUSIONS}

Assessment of how different pavement condition parameters affect crash rates at signalized intersections showed that for both before and after treatment crash rate increases with pavement roughness. However, with increased rutting a reduction in crash rate was observed. Furthermore, higher crash rates were observed during daytime and in dry surface than during night-time and in wet surface. The variation in crash rates with skid resistance for both before and after treatment indicated lower crash rates at higher SFC categories.

Results of EB approach revealed that treatment effect is significant at the $95 \%$ confidence interval in reducing total casualty crashes by $18.1 \%$ and other injury crashes by $11 \%$. However, for high severity crashes the analysis showed that the reduction of $7.3 \%$ is not statistically significant.

\section{REFERENCES}

[1] NZTA, New Zealand Transportation Agency, High Risk Intersection Guide, New Zealand, 2012.

[2] Hauer, E., Terry, D. \& Griffith, M.S., Effect of resurfacing on safety of two-lane rural roads in New York State. Transportation Research Record, 1467, pp. 30-37, 1994.

[3] Abdel-Aty, M., Devarasetty, P.C. \& Pande, A., Safety evaluation of multilane arterials in Florida. Accident Analysis \& Prevention, 41, pp. 777-788, 2009. DOI: 10.1016/j. aap.2009.03.015

[4] Pardillo Mayora, J.M. \& Jurado Pina, R., An assessment of the skid resistance effect on traffic safety under wet-pavement conditions. Accident Analysis \& Prevention, 41, pp. 881-886, 2009. DOI: 10.1016/j.aap.2009.05.004

[5] Zeng, H., Fontaine, M. \& Smith, B., Estimation of the safety effect of pavement condition on rural, two-lane highways. Transportation Research Record: Journal of the Transportation Research Board, pp. 45-52, 2014.

[6] Chan, C.Y., Haung, B., Yan, X. \& Richards, S.H., Effects of asphalt pavement conditions on traffic accidents in Tennessee utilizing pavement management system. 88th Annual Meeting. Washington DC: Transportation Research Board, 2009.

[7] Cairney, P. \& Bennett, P., Relationship between Road Surface Characteristics and Crashes on Victorian Rural Roads. 23rd ARRB Conference, Adelaide, South Australia, 2008.

[8] Larson, R.M., Hoerner, T.E., Smith, K.D. \& Wolters, A.S., Relationship between skid resistance numbers measured with ribbed and smooth tire and wet accident locations. FHWA/OH-2008/11, USA, State Job Number 134323, 2008.

[9] Cairney, P. \& Bennett, P., An exploratory study of surface characteristics and crash occurrence on selected roads in Australia. Victoria, ARRB Group, Research Report 382, 2013.

[10] Tighe, S., Li, N., Falls, L.C. \& Haas, R., Incorporating road safety into pavement management. Transportation Research Record: Journal of the Transportation Research Board, 1699, pp. 1-10, 2000. DOI: 10.3141/1699-01

[11] Cairney, P., Styles, E. \& Bennett, P., Relationship between rutting, other road characteristics and crashes. ARRB Group, Contract Report VC 71038-1, 2005.

[12] Candappa, N., Scully, J., Newstead, S. \& Corben, B., Findings on the effectiveness of intersection treatments included in the Victorian state wide accident black spot program. Melbourne. Australasian Conference on Road Safety. Monash University Accident Research Centre, 2007. 
[13] Saplioglu, M., Eriskin, E., Yuzer, E. \& Aktas, B., Investigation skid resistance effects on traffic safety at urban intersections. 10th International Congress on Advances in Civil Engineering, Ankara, Turkey, 2012.

[14] Simpson, C. \& Eng, B., Performance of high skid resistant surfaces crash trends, VicRoads, Australia, 2005.

[15] Khattak, A., Injury severity in multivehicle rear-end crashes. Transportation Research Record: Journal of the Transportation Research Board, 1,746, pp. 59-68, 2001. DOI: 10.3141/1746-08

[16] Yan, X., Radwan, E. \& Abdel-Aty, M., Characteristics of rear-end accidents at signalized intersections using multiple logistic regression model. Accident Analysis and Prevention, 37(6), pp. 983-995, 2005. DOI: 10.1016/j.aap.2005.05.001

[17] Wang, X. \& Abdel-Aty M., Analysis of left-turn crash injury severity by conflicting pattern using partial proportional odds models, Accident Analysis \& Prevention, 40(5), pp. 1674-1682, 2008. DOI: 10.1016/j.aap.2008.06.001

[18] Hollo, P. \& Kajtar K., Rutting survey with value analysis. Save International Proceeding, 2000.

[19] Golob, T.F. \& Recker W.W., Relationships among urban freeway accidents, traffic flow, weather, and lighting conditions, Journal of Transportation Engineering, 129(4), pp. 342-353, 2003. DOI: 10.1061/(ASCE)0733-947X(2003)129:4(342)

[20] Austroads, Road safety engineering risk assessment: Part 7: Crash Rates Database, AP-T152/10, Sydney, Australia, 2010.

[21] VicRoads, Surface inspection rating procedure for pavements surfaced with sprayed seals and asphalt, VicRoads, Melbourne/Australia, 2004.

[22] Hauer, E., Harwood, D., Council, F. \& Griffith, M., Estimating safety by the Empirical Bayes method: A tutorial. Transportation Research Record: Journal of the Transportation Research Board, pp. 126-131, 2002.

[23] Persaud, B. \& Lyon, C., Empirical Bayes before-after safety studies: Lessons learned from two decades of experience and future directions. Accident Analysis \& Prevention, 39, pp. 546-555, 2007. DOI: 10.1016/j.aap.2006.09.009

[24] Gross, F., Persaud, B. \& Lyon, C., A guide to developing quality crash modification factors, 2010.

[25] Highway Safety Manual, American Association of State Highway and Transportation Officials (AASHTO). Washington, DC, 2010.

[26] Lord, D. \& Persaud, B., Accident prediction models with and without trend: application of the generalized estimating equations procedure. Transportation Research Record: Journal of the Transportation Research Board, 1717(1), pp. 102-108. 